\title{
PERANCANGAN SISTEM INFORMASI PENGELOLAAN MASJID BERBASIS JAVA PADA MASJID AL-IKHLAS PONDOKAREN
}

\author{
Erwin Haryono ${ }^{1}$, Ika Mei Lina ${ }^{2}$, Endaryono ${ }^{3}$ \\ Program Studi Informatika, Fakultas Teknik dan Ilmu Komputer, Universitas Indraprasta PGRI \\ Jalan Raya Tengah No 80, Kelurahan Gedong, Pasar Rebo, Jakarta Timur \\ ewinharyono@gmail.com ${ }^{1}$, ikameilina24@gmail.com², endaryono612@gmail.com³
}

\begin{abstract}
Abstrak
Pada pengelolaan keuangan masjid saat ini masih banyak ditemui sistem pengelolaan keuangannya yang masih manual sehingga banyak menimbulkan kesulitan dalam dewan kemakmuran masjid melaksanakan tugas pengelolaan data dan keuangan masjid. Perancangan sistem informasi pengelolaan masjid pada Masjid Al-Ikhlas Pondok Aren bertujuan meningkatkan kinerja dewan kemakmuran masjid dalam mengelola datadata masjid seperti pendataan data petugas, data donatur, data penerima donasi, pendanaan kas masuk, penyaluran dana masjid serta pembuatan laporan-laporan masjid. Metode dalam penelitian yang digunakan sebagai dasar untuk membuat rancangan sistem informasi pengelolaan masjid ini adalah dengan menggunakan metode analisis dan observasi lapangan. Sistem informasi masjid ini berbasis Java dengan database MySQL membuat sistem informasi pada masjid menjadi lebih efektif, efisien dan aman serta dapat diakses oleh siapapun sesuai dengan kategori masing-masing. Diharapkan dengan pembuatan sistem informasi pada Masjid Al-Ikhlas bisa meningkatkan kinerja dalam pengelolaan masjid.
\end{abstract}

Kata Kunci: Sistem Informasi, Pengelolaan Masjid, Berbasis Java

\begin{abstract}
In the financial management of the mosque today is still found a lot of finance management system that is still manual so that many cause difficulties in the mosque's Prosperity Council carry out the tasks of data management and the finance of mosques. The design of the mosque management information system at Masjid Al-Ikhlas Pondok Aren aims to increase the performance of the mosque's Prosperity council in managing the mosques data such as Officer data collection, donor data, donation recipient data, cash entry financing, mosque fund channeling and mosque report generation. The method in the research used as a basis for the design of the mosque management information system is to use the method of analysis and field observation. The Java-based information System with MySQL databases makes the information system in the mosque more effective, efficient and safe and accessible to anyone according to their respective categories. Hopefully with the creation of information system in Masjid Al-Ikhlas can improve performance in the management of mosques.
\end{abstract}

Keywords: Information Systems, Mosque Management, Java Based

\section{PENDAHULUAN}

Teknologi informasi berkembang begitu pesat guna menunjang kebutuhan manusia akan akses segala bentuk informasi. Penggunaan teknologi informasi telah mampu mempercepat layanan serta ekspansi layanan edukasi bagi masyarakat. Kondisi sistem informasi pengelolaan masjid yang kita amati sekarang, untuk pengelolaan pendataan dan keuangan masjid masih sebagian besar menggelolanya dengan sistem manual. Sehingga pelayanan sistem informasi pengelolaan pada masjid belum memberikan pelayanan yang maksimal kepada masyakarat.

Oleh karena itu, mendorong Masjid Al-Ikhlas untuk merevolusi sistemnya untuk memberikan pelayanan informasi yang mudah diakses dan up to date dengan sistem informasi pengelolaan masjid. Perancangan sistem informasi pengelolaan masjid pada Masjid Al-Ikhlas Pondok Aren dimaksudkan agar dapat meningkatkan kinerja dewan kemakmuran masjid dalam mengelola datadata masjid seperti pendataan data petugas, data donator, data penerima donasi, pendanaan kas masuk, penyaluran dana masjid serta pembuatan laporan-laporan masjid agar lebih efisien, efektif dan aman. Sistem adalah kumpulan atau group dari subsistem/bagian/komponen apapun baik psikis atau non psikis yang saling berhubungan satu sama lain dan bekerja sama secara harmonis untuk mencapai satu tujuan tertentu (Susanto, 2017). Informasi adalah data yang telah diklasifikasi atau diolah atau diinterpretasi untuk digunakan dalam proses pengambilan keputusan (Sutabri, 2016). 


\section{PENELITIAN RELEVAN}

Beberapa penelitian yang relevan dengan penelitian ini adalah:

Penelitian oleh (Fahmi, 2018) dengan judul "Sistem Dana Zakat, Infaq dan Shodaqoh Berbasis Java Pada Masjid Jami Al-Anwar". Hasil penelitian menunjukan bahwa dengan adanya system informasi ini, memudahkan tata cara proses perhitungan keuangan masjid (zakat, infaq, shodaqoh) dengan lebih cepat, tepat dan akurat. Penelitian oleh (Welim \& Sakti, 2016) dengan judul "Rancang Bangun Sistem Informasi Administrasi Pengelolaan Dana Masjdi pada Yayasan Al-Muhajirin Tangerang". Hasil penelitian menunjukan bahwa dengan adanya sistem informasi ini, pengguna dapat memperoleh informasi masjid dengan lebih cepat, tepat dan akurat.

\section{METODE PENELITIAN}

Metode penelitian yang digunakan adalah metode grounded, yaitu suatu metode penelitian yang berdasarkan pada fakta dan menggunakan analisa perbandingan dengan tujuan mengadakan generalisasi empiris, menetapkan konsep, mengembangkan teori, pengumpulan dan analisis data dalam waktu yang bersamaan (Gunawan, 2014). Untuk mendapatkan data dan informasi guna mendukung penyempurnaan hasil dari penelitian ini, maka peneliti melakukan metode pengumpulan yang di antara lain :

1. Metode Interview (Wawancara)

Teknik wawancara yang digunakan dalam penelitian ini adalah menggunakan teknik wawancara yang terstruktur. Proses wawancara dilakukan secara terencana untuk mendapatkan informasi dari nara sumber Bapak Mustopa,S.Sos.I yang menjabat sebagai Ketua DKM (Dewan Kemakmuran Masjid) pada Masjid Al-Ikhlas.

2. Metode Observasi (Pengamatan Langsung)

Observasi yang peneliti lakukan adalah dengan mengamati secara langsung proses sistem yang berjalan pada Masjid Al-Ikhlas agar dapat menentukan kebutuhan sistem yang akan dirancang.

3. Metode Studi Kepustakaan (Literature)

Metode studi kepustakaan sangat bermanfaat dalam metode pengumpulan data untuk penelitian kualitatif yang peneliti butuhkan, dengan cara sebagai berikut :

a) Mempelajari buku-buku mengenai perancangan, implementasi dan desain sebuah aplikasi.

b) Mempelajari buku-buku Pemrograman Java dan Database MySQL.

\section{HASIL DAN PEMBAHASAN}

Data Flow Diagram atau Diagram Alir Data adalah refresentasi grafik yang menggambarkan aliran informasi dan transformasi informasi yang diaplikasikan sebagai data yang mengatur dari masukan (input) dan keluaran (output) (Sukamto \& Shalahuddin, 2016). Berikut ini merupakan gambaran tentang sistem yang diusulkan pada perancangan sistem informasi Masjid Al-Ikhlas secara keseluruhan dalam bentuk diagram konteks :

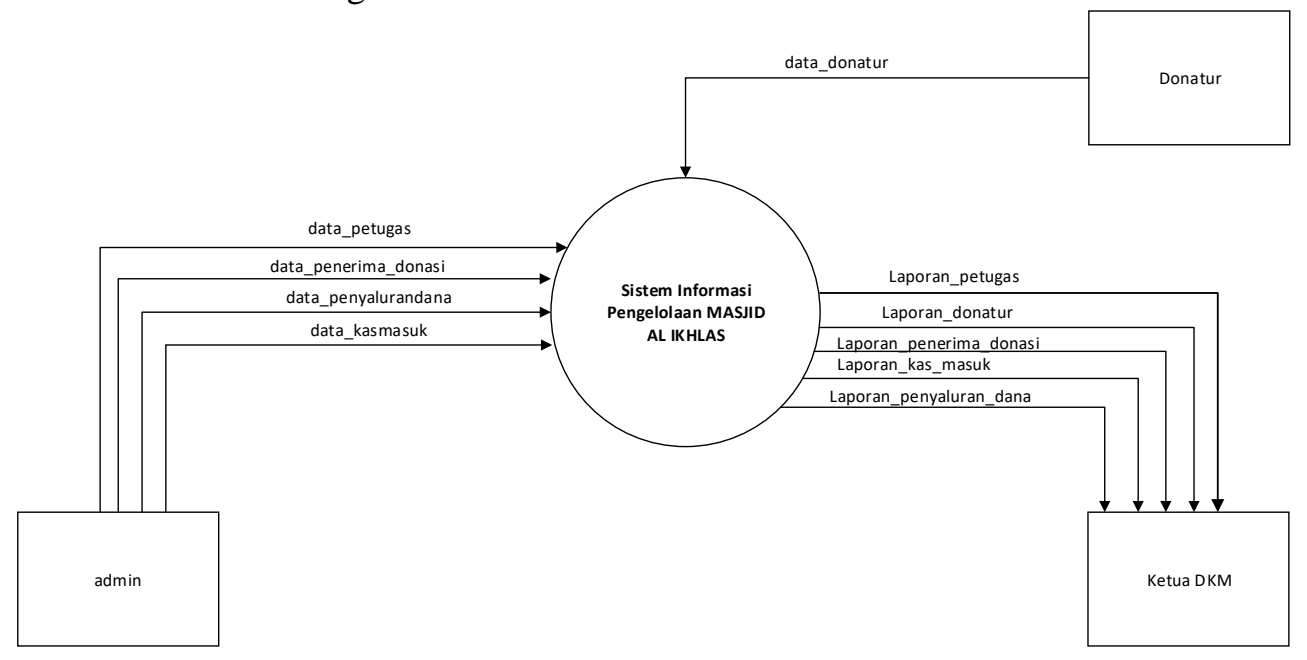

Gambar 1. Diagram Konteks Sistem yang Diusulkan 
Pada Diagram Konteks yang diusulkan, admin bertugas untuk menginput data petugas, data penerima donasi, data penyaluran dana dan data kas masuk. Bagi donatur sendiri dapat menginput data donatur sendiri dengan akses yang diberikan dalam sistem. Setiap dalam pengelolaan akan dibuat laporan yang akan diakses atau diperiksa oleh ketua dewan kemakmuran masjid.

Entity Relationship Diagram (ERD) adalah suatu permodelan berbasis pada persepsi dunia maya yang mana terdiri dari kumpulan objek dasar yang disebut dengan entitas dan hubungan diantara objek-objek tersebut dengan menggunakan perangkat konseptual dalam bentuk diagram (Adyanata, 2016). Berikut ini merupakan gambaran tentang sistem yang diusulkan pada perancangan sistem informasi Masjid Al-Ikhlas secara keseluruhan dalam bentuk entity relationship diagram :

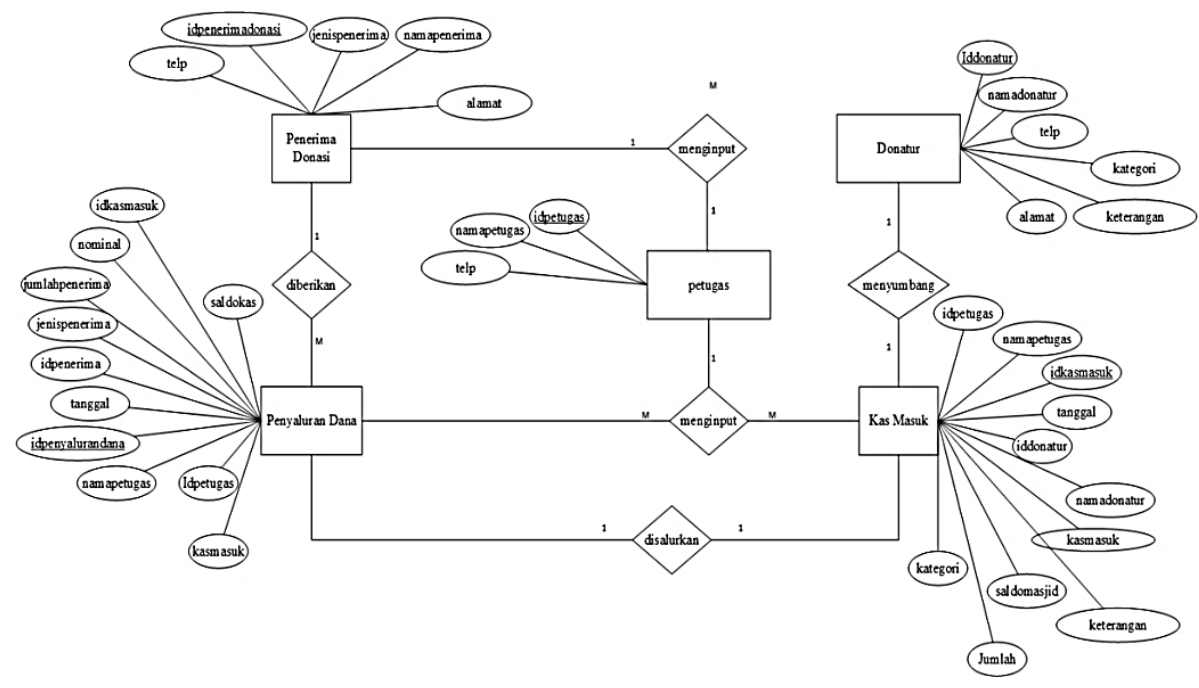

Gambar 2. ERD Sistem yang Diusulkan

Pada entity relationship diagram menjelaskan bahwa donatur menyumbangkan sejumlah uang yang akan dicatat pada kas masuk, admin yang bertugas mendata memasukan data sumbangan donatur pada kas masuk lalu mengelolanya hingga penggunaan pada penyaluran keuangan tepat diberikan kepada penerima donasi yang sudah terdata.

\section{Tampilan Layar, Tampilan Format Masukan Dan Tampilan Keluaran}

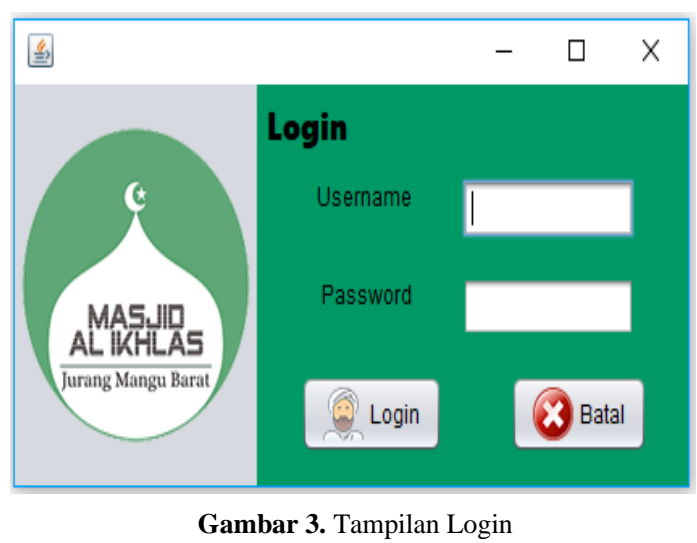

Pada tampilan menu login, setiap akses akan diarahkan untuk mengisi username dan password sesuai akses yang sudah ditentukan. 


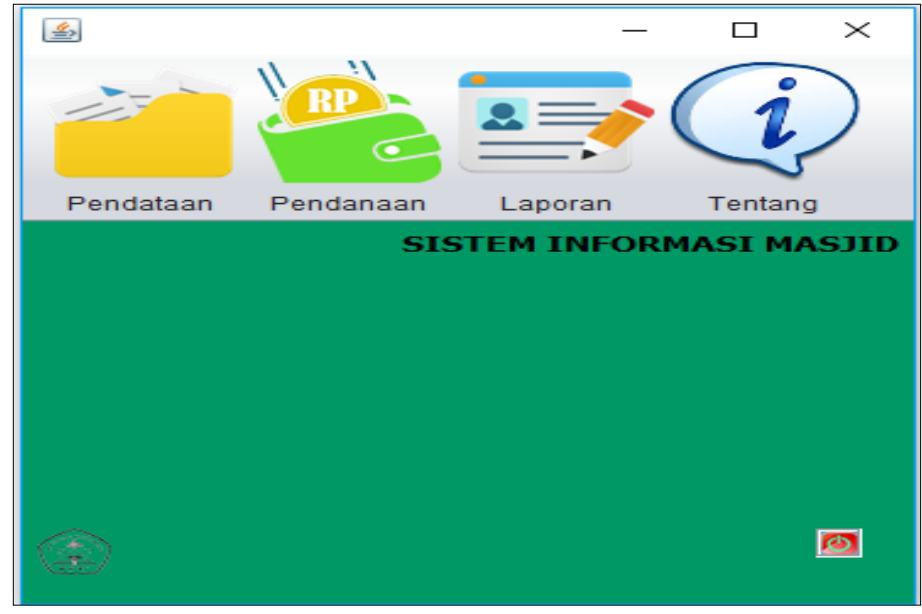

Gambar 4. Tampilan Menu Utama Admin

Pada tampilan menu admin terdapat pendataan, pendanaan, laporan serta informasi tentang program.

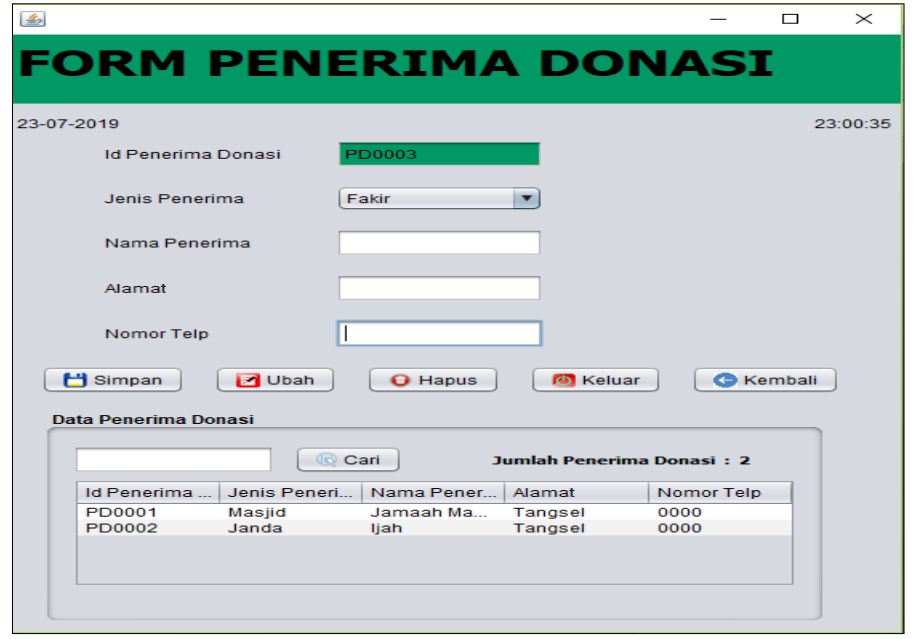

Gambar 5. Tampilan Form Penerima Donasi

Pada tampilan form penerima donasi, admin bertugas menginput data penerima donasi dan setiap data penyaluran dana akan diberikan kepada penerima donasi yang sudah terdaftar.

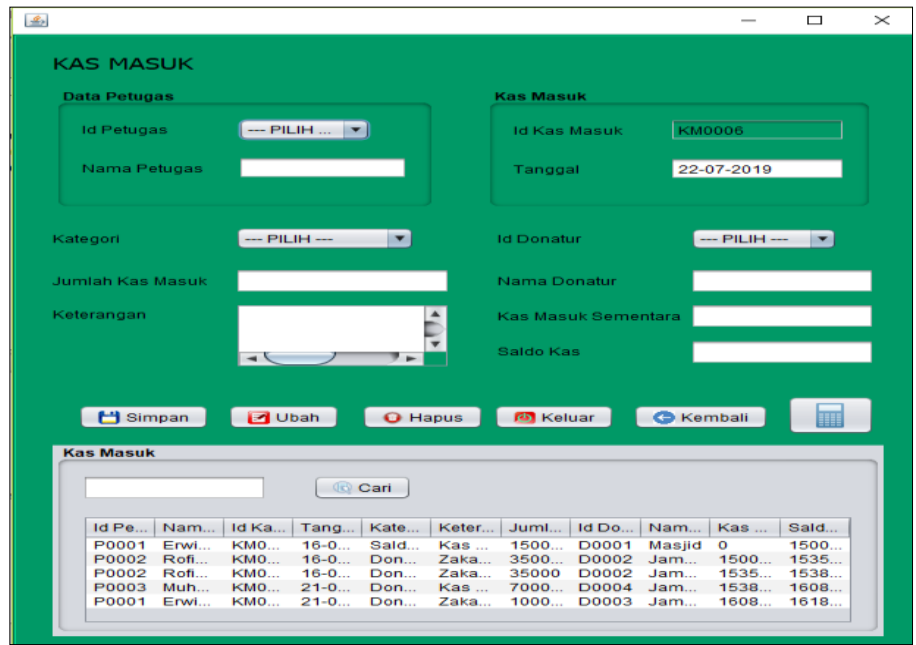

Gambar 6. Tampilan Form Penerima Donasi 
Pada tampilan form kas masuk, admin bertugas menginput data kas masuk dengan data keuangan yang didapat dari sumbangan donatur.

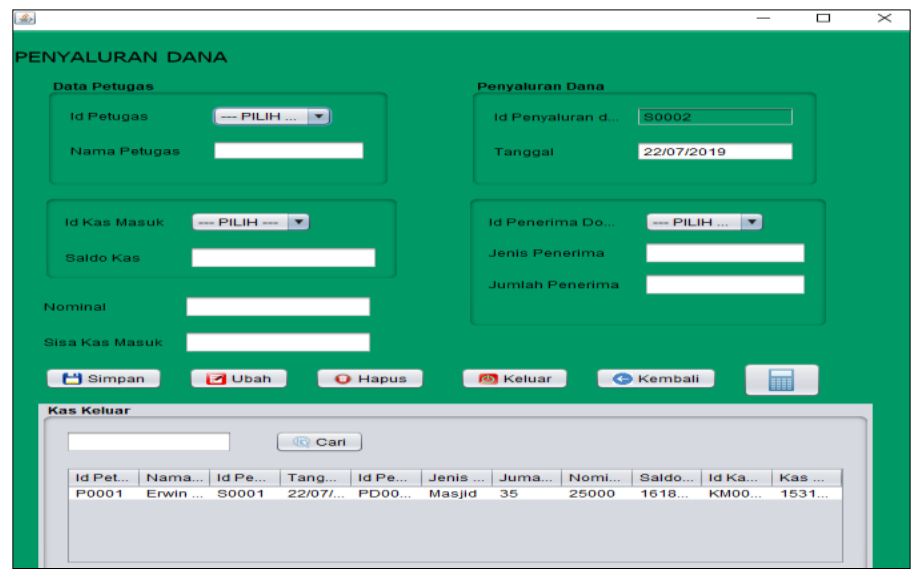

Gambar 7. Tampilan Form Penyaluran Dana

Pada tampilan form kas masuk, admin bertugas menginput data penyaluran dana masjid yang disesuaikan dengan data keuangan yang ada, lalu disalurkan kepada penerima donasi sesuai data penerima donasi yang terdaftar.

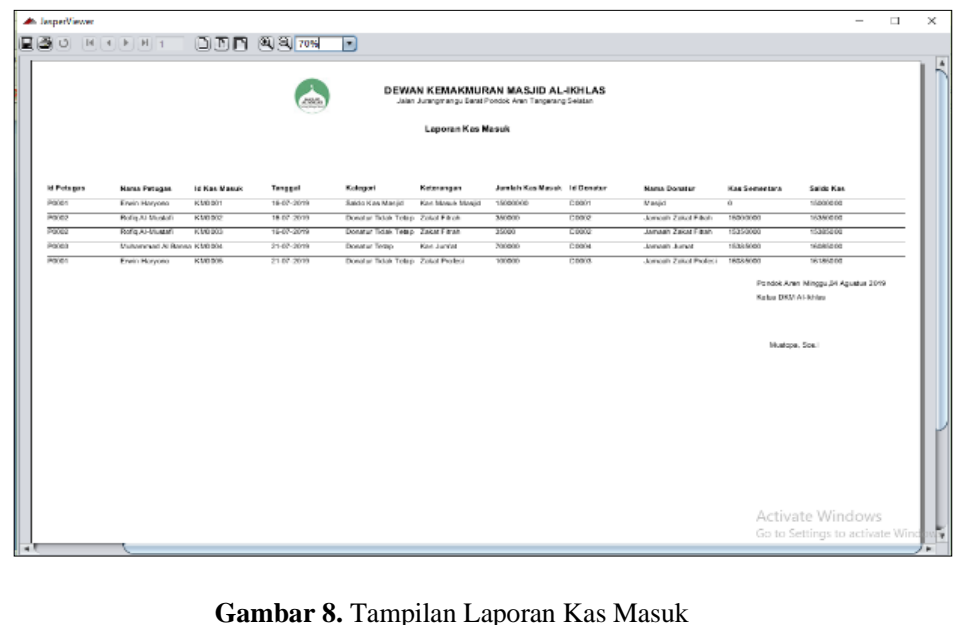

Pada tampilan laporan kas masuk, laporan ini diberikan kepada ketua dewan kemakmuran masjid untuk digunakan sebagai bukti pada sistem pengelolaan masjid.

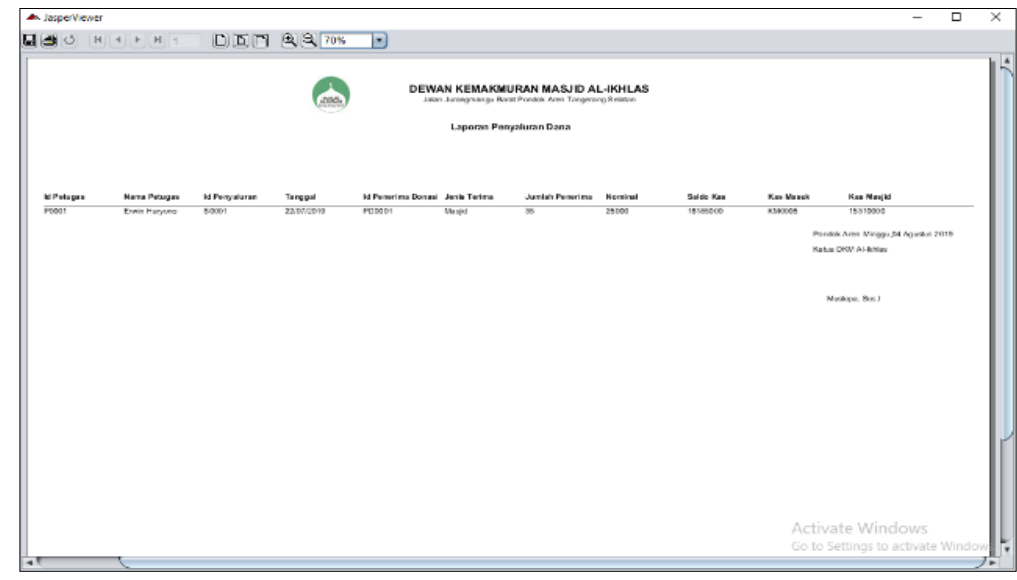

Gambar 9. Tampilan Laporan Penyaluran Dana 
Pada tampilan laporan penyaluran dana, laporan ini diberikan kepada ketua dewan kemakmuran masjid untuk digunakan sebagai bukti pada sistem pengelolaan masjid.

\section{SIMPULAN}

Dengan dibuatnya rancang bangun sistem informasi pengelolaan masjid pada Masjid Al-Ikhlas Pondok Aren, peneliti mempunyai kesimpulan bahwa rancangan aplikasi sistem informasi pengelolaan masjid pada Masjid Al-Ikhlas Pondok Aren dapat lebih cepat, efektif, efisien, aman, terkonsep dan up to date dalam pengolahan datanya, dapat mengurangi terjadinya kesalahan dalam perhitungan keuangan masjid, sistem informasi yang terintegrasi, mudah diakses dan terkomputerisasi serta dapat mempermudah pembutaan laporan secara terperinci dan akurat.

\section{DAFTAR PUSTAKA}

Adyanata, L. (2016). Basis Data Dasar. In Deepublish.

Fahmi, A. Z. (2018). Sistem Dana Zakat; Infaq dan Shodaqoh Berbasis Java Pada Masjid Jami. Universitas Indraprasta PGRI.

Gunawan, I. (2014). Metode Penelitian Kualitatif: Teori dan Praktik. Jakarta: Bumi Aksara.

Isa, I. (2014). Pentingnya Sistem Informasi Dalam Keberhasilan Sebuah Proyek. Yogyakarta : Graha Ilmu.

Sukamto, R. A., \& Shalahuddin, M. (2016). Rekayasa Perangkat Lunak (Terstruktur dan berbasis objek). Sdlc.

Susanto, A. (2017). Sistem Informasi Manajemen (Konsep dan Pengembangan Secara Terpadu). Bandung : Lingga Jaya.

Sutabri, T. (2016). Sistem Informasi Manajemen (Edisi Revisi). Yogyakarta : ANDI Yogyakarta.

Welim, Y. Y., \& Sakti, A. R. (2016). Rancang Bangun Sistem Informasi Administrasi Pengelolaan Dana Masjid Pada Yayasan Al-Muhajiriin, Tangerang. Simetris: Jurnal Teknik Mesin, Elektro Dan Ilmu Komputer, 7(1), 29. https://doi.org/10.24176/simet.v7i1.485 